\title{
АНАЛИЗ УГЛОВЫХ ОТКЛОНЕНИЙ МЕЖДУ ОСЯМИ ДЕНТАЛЬНЫХ ИМПЛАНТАТОВ, УСТАНОВЛЕННЫХ ПО КЛАССИЧЕСКОЙ МЕТОДИКЕ
}

\author{
А. В. Иващенко, А. Е. Яблоков ${ }^{凶}$, И. М. Федяев, В. П. Тлустенко, Н. Е. Ротин, В. В. Тугушев \\ Самарский государственный медицинский университет, Самара, Россия
}

\begin{abstract}
Наиболее распространенной сложностью при постановке имплантатов является затрудненный выбор пространственного положения имплантатов. При интеграции имплантатов в полость рта две трети успеха операции зависят от того, насколько точно врач выберет позицию и угол наклона имплантата. Одной из важных проблем при установке имплантатов является их позиционирование в костном ложе. Целью работы было провести сравнительный анализ угловых отклонений дентальных имплантатов, установленных по классической методике, по «методу свободной руки» («free hand»). Использовали следующий алгоритм исследования. В декартовой системе координат на КТ-снимке в плоскости ХОҮ (горизонтальная плоскость) определяли координаты шеек сравниваемых имплантатов у 34 исследуемых пациентов. Затем находили координаты апикальных частей всех исследуемых имплантатов. Полученные координаты помещали в разработанную нами программу ЭВМ № 2018661716 «Программа расчета угловых отклонений дентальных имплантатов", которая автоматически вычисляла угловое отклонение между осями установленных имплантатов. Расчет угловых отклонений между осями дентальных имплантатов у пациентов в послеоперационном периоде показал в $87 \%$ случаев значительное отклонение угла (до $27^{\circ}$ ) между осями имплантатов по сравнению с общепринятыми в дентальной имплантологии пределами (до $7^{\circ}$ ). В 100\% изучаемых случаев не было отмечено параллельной установки дентальных имплантатов; анализ результатов дентальной имплантации в 1-м секторе выявил угловые отклонения в $27^{\circ} 4$.
\end{abstract}

Ключевые слова: дентальная имплантация, навигационная платформа, метод свободной руки

Информация о вкладе авторов: А. В. Иващенко - написание статьи, разработка дизайна исследования, подбор клинического материала; А. Е. Яблоков - написание статьи, подбор клинического материала, анализ полученных данных; И. М. Федяев - разработка дизайна исследования, редактирование статьи; В. П. Тлустенко - редактирование, анализ полученных данных; Н. Е. Ротин - разработка дизайна исследования, подбор клинического материала; В. В. Тугушев - разработка дизайна исследования, редактирование.

Соблюдение этических стандартов: исследование проведено в соответствии с этическими стандартами оказания специализированной медицинской помощи (Приказ Министерства здравоохранения России от 24 декабря 2012 г. № 1525н) и одобрено этическим комитетом Самарского государственного медицинского университета (протокол № 673/17 от 11 сентября 2018 г.). Все пациенты подписали информированное согласие на участие в исследовании.

Для корреспонденции: Алексей Евгеньевич Яблоков

ул. Чапаевская, д. 89, г. Самара, 443099; s1131149@уandex.ru

Статья получена: 26.10.2018 Статья принята к печати: 04.04.2019 Опубликована онлайн: 15.04.2019

DOI: $10.24075 /$ vrgmu.2019.027

\section{ANALYSIS OF DIVERGENCE BETWEEN THE AXES OF DENTAL IMPLANTS INSTALLED USING A CLASSIC FREEHAND TECHNIQUE}

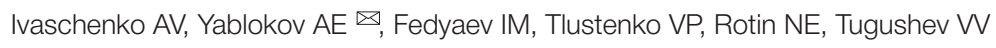

Samara State Medical University, Samara, Russia

Accuracy is a common challenge in dental implant placement. A successful clinical outcome is largely determined by accurate positioning of the implant at the prepared site and proper angulation. This study aimed to compare the divergence between the axes of the implants installed using a classic freehand technique. Cartesian coordinates of implant necks were determined on the CT images of 34 patients in the XOY (horizontal) plane, followed by the coordinates of implant apices. The obtained data were submitted to the original software developed by the authors (patent 2018661716) that automatically computed an angle between the insertion axes of the installed implants. We found that in $87 \%$ of cases, this angle was significantly greater (up to $27^{\circ}$ ) than recommended by implantation dentistry guidelines $\left(7^{\circ}\right)$. In $100 \%$ of the studied cases, the implants were not parallel; in sector 1 , the deviation was $27^{\circ} 4^{\prime}$.

Keywords: dental implantation, navigation system, freehand placement

Author contribution: Ivaschenko AV — study design, data acquisition, manuscript draft; Yablokov AE — data acquisition and analysis, manuscript draft; Fedyaev IM — study design, manuscript editing; Tlustenko VP — data analysis, manuscript editing; Rotin NE — study design, data acquisition; Tugushev VV — study design, manuscript editing.

Compliance with ethical standards: this study was conducted in compliance with the ethical standards for specialized medical care (Order $1525 \mathrm{n}$ of the Ministry of Healthcare of the Russian Federation, dated December 2012) and approved by the Ethics Committee of Samara State Medical University (Protocol 673/17 dated September 11, 2018). The patients gave written informed consent to participate.

$\triangle$ Correspondence should be addressed: Alexey E. Yablokov Chapaevskaya 89, Samara, 443099; s1131149@yandex.ru

Received: 26.10.2018 Accepted: 04.04.2019 Published online: 15.04.2019

DOI: 10.24075/brsmu.2019.027

Правильная позиция и осевое расположение имплантата одни из составляющих элементов успеха лечения, т. е. длительного функционирования имплантата и ортопедической конструкции. Самым распространенным способом установки дентальных имплантатов и «золотым стандартом» отечественной имплантологии является метод «Свободной руки» («free hand») [1]. Врач, руководствуясь своими знаниями и опытом, делает заключение о точном месте позиционирования дентальных имплантатов. Проблема неправильного позиционирования дентальных имплантатов актуальна в современной стоматологии, поскольку от угла установки дентального имплантата зависит успешность ортопедического лечения в дальнейшем. По современным стандартам допустимый угол отклонения имплантата составляет $7^{\circ}$ [1]. Ряд авторов отмечает, что в клинической практике при применении данного метода погрешность позиционирования имплантата может достигать $35^{\circ}$ [2].

Для решения данной проблемы в клинической имплантологии применяют навигационные шаблоны 
и дентальные навигационные платформы [3, 4]. Применение данных методов позволяет позиционировать имплантаты с допустимой погрешностью до $7^{\circ}$ [5-7]. Указанные методы не получили широкого применения в связи с высокой стоимостью и необходимостью иметь специально обученную команду специалистов, умеющих работать с данными системами [8-11]. Таким образом, в настоящее время наиболее распространенным методом позиционирования дентальных имплантатов является метод «free hand", который при отсутствии должных навыков у врача накладывает значительный негативный отпечаток на результат лечения [12-15].

Для оценки стабильности дентальных имплантатов применяют прямые цифровые методы. Они позволяют оценить степень остеоинтеграции установленных имплантатов. K таким методам относят периотестометрию с использованием аппаратов Periotest и Osstell ISQ [16, 17].

Целью работы было провести сравнительный анализ угловых отклонений дентальных имплантатов, установленных по классической методике («free hand»).

\section{ПАЦИЕНТЫ И МЕТОДЫ}

Сбор клинического материала проводили на базе отделения челюстно-лицевой хирургии Самарского государственного медицинского университета в период с 2015 по 2018 г. Все пациенты проходили комплексное обследование. Происходящие изменения фиксировали в медицинской карте стоматологического больного (форма 043/y-4). Обследование включало сбор анамнеза, жалоб, вредных привычек, выяснение сопутствующих заболеваний, которые могут стать причиной осложнений и противопоказаний к операции дентальной имплантации. Исследуемая группа включала 32 пациента, которым была проведена дентальная имплантация по методу «free hand». Критерии отбора пациентов: пациенты любого пола; возраст 18-65 лет; частичное отсуствие зубов; отсутствие соматической патологии. Основной контингент пациентов (53,1\%), которым была проведена операция дентальной имплантации по классической методике, составили женщины в возрасте 26-44 лет (табл. 1). Пациентам проводили компьютерно-томографическое исследование с применением томографра Vatech Pax Duo (Vatech; Kopeя).

\section{РЕЗУЛЬТАТЫ ИССЛЕДОВАНИЯ}

После установки дентальных имплантатов оценивали наличие жалоб, болевого синдрома, температуру тела, конфигурацию лица, клиническую картину тканей в периимплантационной области, экскурсию имплантата, состояние линии швов и формирователей десны.

Дентальные имплантаты (MISS и DENTIUM; Израиль) устанавливали по традиционному двухэтапному хирургическому протоколу. Установку имплантатов всем пациентам проводил хирург-имплантолог. Распределение дентальных имплантатов по диаметру и количеству в исследуемой группе представлено в табл. 2.

Методом случайной выборки у 10 пациентов было проведено компьютерно-томографическое исследование с применением томографра Vitech Pax Duo c целью определения среднего углового отклонения между осями установленных имплантатов. Расчет угловых отклонений между осями имплантатов проводили по следующему математическому алгоритму (программа ЭВМ № 2018661716):

$\alpha=\arccos \frac{|(\vec{a}, \vec{b})|}{|\vec{a}| \cdot|\vec{b}|}=\arccos \frac{\left|a_{x} \cdot b_{x}+a_{y} \cdot b_{y}+a_{z} \cdot b_{z}\right|}{\sqrt{a_{x}^{2}+a_{y}^{2}+a_{z}^{2}}, \cdot \sqrt{b_{x}^{2}+b_{y}^{2}+b_{z}^{2}}}$, где

$\vec{a}=\left(a_{x}, a_{y}, a_{z}\right)$ и $\vec{b}=\left(b_{x}, b_{y}, b_{z}\right)$,

$\cos \alpha=\frac{|(\vec{a}, \vec{b})|}{|\vec{a}| \cdot|\vec{b}|}=\frac{\left|a_{x} \cdot b_{x}+a_{y} \cdot b_{y}+a_{z} \cdot b_{z}\right|}{\sqrt{a_{x}^{2}+a_{y}^{2}+a_{z}^{2}}, \cdot \sqrt{b_{x}^{2}+b_{y}^{2}+b_{z}^{2}}}$.

В результате исследования была проанализирована позиция 22 установленных имплантатов у 10 пациентов.

Алгоритм исследования проводили следующим образом. В декартовой системе координат на компьютерно-томографическом снимке в плоскости ХOY

Таблица 1. Характеристика пациентов по возрастному и гендерному признакам

\begin{tabular}{|c|c|c|c|c|c|}
\hline Позраст & $18-25$ & $26-44$ & $45-65$ & Всего Количество пациентов, \% \\
\hline Мужчины & 1 & 3 & 4 & 8 & 25 \\
\hline Женщины & 1 & 17 & 6 & 24 & 35 \\
\hline Всего & 2 & 20 & 10 & 100 \\
\hline
\end{tabular}

Таблица 2. Соотношение количества установленных дентальных имплантатов с их диаметром

\begin{tabular}{|c|c|c|c|c|c|}
\hline Диаметр & Один имплантат & Два имплантата & Три имплантата & Всего & Количество, \% \\
\hline 3,3 • 10,0 («MISS») & 4 & 2 & 0 & 6 & 16,2 \\
\hline 3,6 • 7,0 («Dentium») & 0 & 1 & 0 & 1 & 2,7 \\
\hline 3,75 • 8,0 («MISS») & 6 & 2 & 0 & 8 & 21,6 \\
\hline 3,75 • 10,0 («MISS») & 2 & 2 & 0 & 4 & 10,8 \\
\hline 3,75 • 11,5 («MISS») & 5 & 1 & 0 & 6 & 16,2 \\
\hline 4,0 • 10,0 («MISS») & 0 & 0 & 1 & 1 & 2,7 \\
\hline 4,2 • 8,0 («MISS») & 4 & 1 & 0 & 5 & 13,5 \\
\hline 4,2 • 10,0 («MISS») & 3 & 0 & 0 & 3 & 8,1 \\
\hline 4,2 • 11,5 («MISS») & 3 & 0 & 0 & 3 & 8,1 \\
\hline Всего & 27 & 9 & 1 & 37 & 100,0 \\
\hline
\end{tabular}



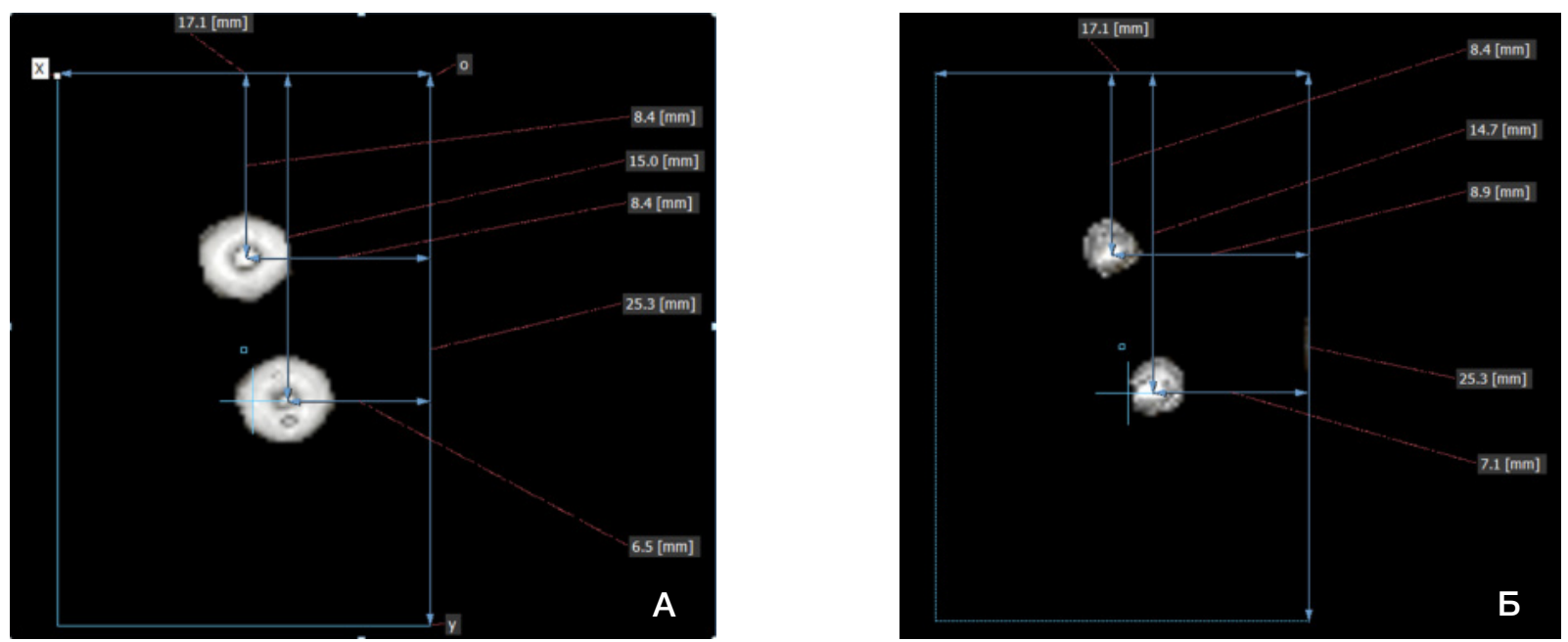

Рис. 1. Схематичное изображение системы измерений авторской программы ЭВМ. А. Координаты шеек сравниваемых имплантатов. Б. Координаты апикальных частей исследуемых имплантатов

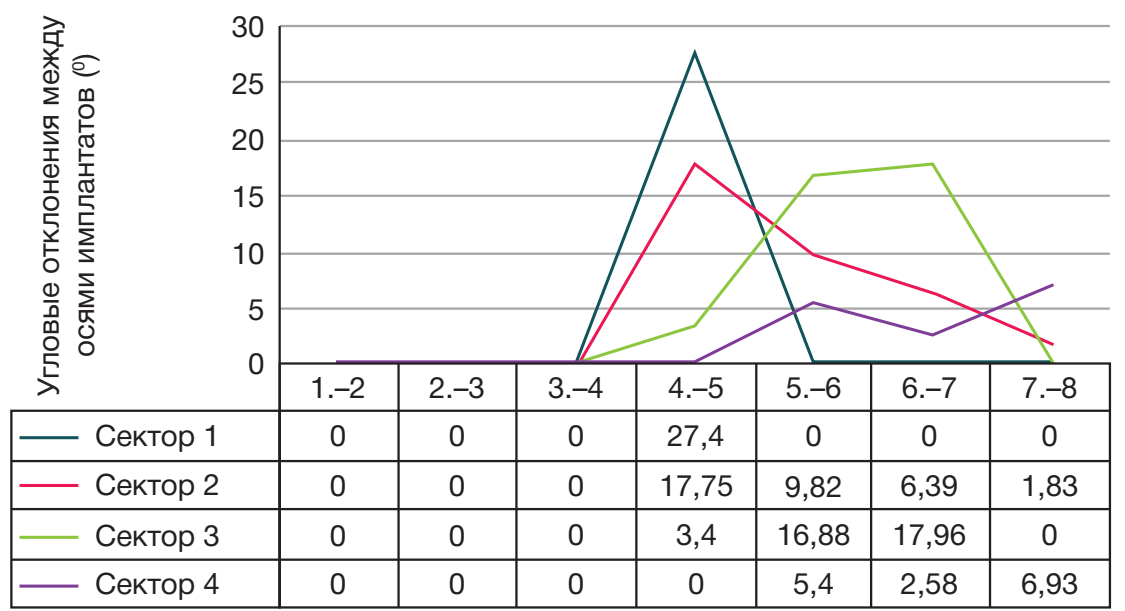

Рис. 2. Статические значения расчетных показателей угловых отклонений

(горизонтальная плоскость) определяли координаты шеек сравниваемых имплантатов (рис. 1А). Затем находили координаты апикальных частей всех исследуемых имплантатов (рис. 1Б). Полученные координаты помещали в разработанную нами программу (патент на ЭВМ № 2018661716 от 12 сентября 2018 г.), которая автоматически вычисляла угловое отклонение между осями установленных имплантатов.

Полученные данные структурировали и подвергали анализу, в результате которого была выявлена динамика угловых отклонений дентальных имплантатов в исследуемой группе.

В 100\% изучаемых случаев не было отмечено параллельной установки дентальных имплантатов. В 4-м секторе были отмечены наименьшие угловые отклонения между осями установленных имплантатов. Средний угол конвергенции между осями имплантатов варьировал В пределах от $2^{\circ} 58^{\prime}$ до $5^{\circ} 4^{\prime}$. В связи с этим можно сделать заключение, что данный диапазон соответствует общепринятым параметрам угловых отклонений при дентальной имплантации. Во 2-м и 3-м секторах был отмечен диапазон среднего угла конвергенции от $3^{\circ} 4^{\prime}$

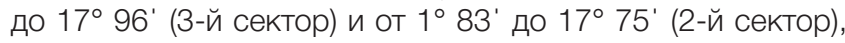
что свидетельствует об неудовлетворительных угловых отклонениях. Анализ результатов дентальной имплантации в 1-м секторе выявил угловые отклонения в $27^{\circ} 4^{\prime}$. Cкорее всего, это связано со сложным анатомическим доступом.
Таким образом, можно сделать вывод, что наибольшие угловые отклонения наблюдались в 1-м секторе.

\section{ОБСУЖДЕНИЕ}

Расчет угловых отклонений между осями дентальных имплантатов у пациентов в послеоперационном периоде показал в 87\% случаев значительное отклонение угла $\left(27^{\circ} 4^{\prime}\right)$ между осями имплантатов по сравнению с общепринятыми в дентальной имплантологии пределами (рис. 2). Под осью имплантата понимали геометрический центр фигуры правильной цилиндрической формы в виде имплантата.

Наибольшие угловые отклонения между осями установленных дентальных имплантатов можно наблюдать в проекции первого сектора, что согласуется с данными ряда авторов [6, 12, 15]. Минимальные статистически достоверные показатели составляли $\pm 0,5^{\circ}$. В настоящем исследовании зубной ряд пациентов для удобства расчета делили на четыре квадранта (сектора) по общепринятой классификации ВОЗ зубных рядов: 1-й сектор - от зуба 1.1 до 1.8; 2-й сектор — от зуба 2.1 до 2.8; 3-й сектор — от зуба 3.1 до 3.8; 4-й сектор - от зуба 4.1 до 4.8.

Четкое понимание и соблюдение допустимых угловых отклонений при дентальной имплантации способствует соблюдению биофизических параметров при дальнейшем ортопедическом лечении, что в свою 
очередь, создает благоприятные условия для физиологического функционирования всей зубочелюстной системы в целом.

\section{ВЫВОДЫ}

В ходе работы научно обоснована динамика угловых отклонений между осями дентальных имплантатов, установленных по классической методике. Дальнейшее развитие темы состоит в усовершенствовании метода «free hand» за счет применения механических устройств, а также полуавтоматических и автоматических систем установки дентальных имплантатов. Рекомендуем предложенную авторскую математическую модель для оценки угловых отклонений между осями дентальных имплантатов.

\section{Литература}

1. Клинические рекомендации (протоколы лечения) при диагнозе полное отсутствие зубов (полная вторичная адентия, потеря зубов вследствие несчастного случая, удаления или локализованного пародонтита). Утверждены постановлением № 15 совета ассоциации общественных объединений «Стоматологическая ассоциация России» от 30 сентября 2014 г. Доступно по ссылке: www.e-stomatology.ru.

2. Потапов И. В., Иващенко А. В., Байриков А. И., Монаков Д. В., Монаков В. А. Обоснование использования навигационной системы в дентальной имплантологии. Институт стоматологии. 2014; (4): 83-5.

3. Амхадова М. А., Игнатов А. Ю. Дентальная имплантация с применением навигационного имплантологического шаблона, изготовленного по технологии CAD/CAM. Стоматология. 2011; (2): 49-52.

4. Олесова В. Н., Кашенко П. В., Бронштейн Д. А., Магамедханов М. Ю., Хавкин В. А. Компьютерное планирование внутрикостной дентальной имплантации. Стоматология. 2011; (2): 43-8.

5. Федяев И. М., Хамадеева А. М., Никольский В. Ю., Ганжа И. Р. Вторичная адентия при дентальной имплантации (эпидемиологическое и социологическое исследование с помощью метода телефонного интервью). Стоматология. 2004; 83 (6): 65-8.

6. Нестеров А. П., Лепилин А. В., Нестеров А. В., Ульянова С. П. Взаимосвязь положения имплантатов в нижней челюсти. Вестник медицинского стоматологического института. 2016; 2 (37): 17-20.

7. Фазуллин Ф. З., Галиева Э. И., Рябых Л. А. Снижение риска развития осложнений дентальной имплантации. В сборнике: Материалы XXIV Международного симпозиума «Инновационные технологии в стоматологии», посвященного 60-летию стоматологического фракультета Омского государственного медицинского университета. Омск: Издательский центр «КАН», 2017; 501-5.

8. Кан И. В., Кареров М. Р., Самотесов П. А., Шевченко Д. П., Мартынчук Д. В. Выбор оптимального диаметра имплантата при непосредственной стоматологической имплантации. Журнал анатомии и гистопатологии. 2018; 7 (1): 47-52.

9. Ушаков Р. В., Коркин В. В., Ушаков А. Р., Ляхович А. А
Комплексная реабилитация пациентов с полным отсутствием зубов. Российский медицинский журнал. 2011; (1): 34-7.

10. Ахмадова А. М., Мохов А. В., Музаева З. Р. Оздемиров М. И., Шалабаева К. З. Способ увеличения кератинизированной десны в области имплантатов с использованием небного соединительнотканного трансплантата. Медицинский алфавит. 2015; 3 (13): 28-30.

11. Саакян Ш. Х., Каламкаров А. Э. Структура изменений в альвеолярной кости при ортопедическом лечении пациентов с дефектами зубных рядов с использованием. Вестник стоматологии и внутрикостных имплантатов. Российский стоматологический журнал. 2014; (2): 13-16.

12. Матвеева А. И., Фролов В. А., Гветадзе Р. Ш., Борисов А. Г. Влияние имплантата параметров на напряженнодеформированное состояние костной ткани зоны имплантации. Стоматология. 2010; (1): 54-5.

13. Чуйко А. Н. и др. Термины: фиксация и стабилизация с позиции биохимического анализа. Молодой ученый. 2013; (9): 98-108.

14. Кончаковский А. В., Кончаковский А. А. Одномоментная имплантация в лунку удаленного зуба и непосредственное предварительное имплантационное протезирование акриловыми конструкциями. Современная наука: актуальные проблемы теории и практики. Серия: Естественные и технические науки. 2018; (7): 199-204.

15. Байриков И. М., Иващенко А. В., Лайва О. В., Кондрашин Д. В., Федяев И. М., Нестеров А. М. Клинические возможности навигационной системы при установке дентальных имплантатов. В сборнике: Актуальные вопросы стоматологии. Сборник научных трудов, посвященный 50-летию стоматологического образования в СамГМУ. 2016; 124-134.

16. Sarmento HR, Dantas RVF, Pereira-Cenci T, Faot F. Elements of implant-supported rehabilitation planning in patients with bruxism. Journal of Craniofacial Surgery. 2012; 23 (6): 1905-9.

17. Ерошин В. А., Джалалова М. В., Арутюнов С. Д., Степанов А. Г., Багдасарян Г. Г. Подвижность и критерии готовности дентальных имплантатов к функциональным нагрузкам. Современные проблемы науки и образования. 2018; (2): 53.

izgotovlennogo po tehnologii CAD/CAM. Stomatologija. 2011; (2): 49-52.

4. Olesova VN, Kashenko PV, Bronshtejn DA, Magamedhanov MYu, Havkin VA. Komp'juternoe planirovanie vnutrikostnoj dental'noj implantacii. Stomatologija. 2011; (2): 43-8.

5. Fedyaev IM, Hamadeeva AM, Nikolskij Wu, Ganzha IR. Vtorichnaja adentija pri dental'noj implantacii (jepidemiologicheskoe i sociologicheskoe issledovanie s pomoshh'ju metoda telefonnogo interv'ju). Stomatologija. 2004; 83 (6): 65-8.

6. Nesterov AP, Lepilin AV, Nesterov AV, Ulyanova SP. Vzaimosvjaz' polozhenija implantatov $v$ nizhnej cheljusti. Vestnik medicinskogo stomatologicheskogo instituta. 2016; 2 (37): 17-20. 
7. Fazullin FZ, Galieva Yel, Rjabyh LA. Snizhenie riska razvitija oslozhnenij dental'noj implantacii. V sbornike: Materialy HHIV Mezhdunarodnogo simpoziuma «Innovacionnye tehnologii v stomatologii», posvjashhennogo 60-letiju stomatologicheskogo fakul'teta Omskogo gosudarstvennogo medicinskogo universiteta. Omsk: Izdatel'skij centr «KAN», 2017; 501-5.

8. Kan IV, Karerov MR, Samotesov PA, Shevchenko DP, Martynchuk DV. Vybor optimal'nogo diametra implantata pri neposredstvennoj stomatologicheskoj implantacii. Zhurnal anatomii i gistopatologii. 2018; 7 (1): 47-52.

9. Ushakov RV, Korkin W, Ushakov AR, Lyahovich AA. Kompleksnaja reabilitacija pacientov s polnym otsutstviem zubov. Rossijskij medicinskij zhurnal. 2011; (1): 34-7.

10. Ahmadova AM, Mohov AV, Muzaeva ZR. Ozdemirov MI, Shalabaeva KZ. Sposob uvelichenija keratinizirovannoj desny v oblasti implantatov $s$ ispol'zovaniem nebnogo soedinitel'notkannogo transplantata. Medicinskij alfavit. 2015; 3 (13): 28-30.

11. Saakjan ShH, Kalamkarov AYe. Struktura izmenenij v al'veoljarnoj kosti pri ortopedicheskom lechenii pacientov s defektami zubnyh rjadov $s$ ispol'zovaniem. Vestnik stomatologii i vnutrikostnyh implantatov. Rossijskij stomatologicheskij zhurnal. 2014; (2): 13-16.

12. Matveeva Al, Frolov VA, Gvetadze RSh, AG. Borisov Vlijanie implantata parametrov na naprjazhenno-deformirovannoe sostojanie kostnoj tkani zony implantacii. Stomatologija. 2010; (1): 54-5.

13. Chuyko AN i dr. Terminy: fiksacija i stabilizacija $s$ pozici biohimicheskogo analiza. Molodoy uchenyy. 2013; (9): 98-108.

14. Konchakovskiy AV, Konchakovskiy AA. Odnomomentnaja implantacija $v$ lunku udalennogo zuba i neposredstvennoe predvaritel'noe implantacionnoe protezirovanie akrilovymi konstrukcijami. Sovremennaja nauka: aktual'nye problemy teorii i praktiki. Serija: Estestvennye i tehnicheskie nauki. 2018; (7): 199-204.

15. Bayrikov IM, Ivashhenko AV, Layva OV, Kondrashin DV, Fedyaev IM, Nesterov AM. Klinicheskie vozmozhnosti navigacionnoj sistemy pri ustanovke dental'nyh implantatov. V sbornike: Aktual'nye voprosy stomatologii. Sbornik nauchnyh trudov, posvjashhennyj 50-letiju stomatologicheskogo obrazovanija v SamGMU. 2016; 124-134.

16. Sarmento HR, Dantas RVF, Pereira-Cenci T, Faot F. Elements of implant-supported rehabilitation planning in patients with bruxism. Journal of Craniofacial Surgery. 2012; 23 (6): 1905-9.

17. Eroshin VA, Dzhalalova MV, Arutjunov SD, Stepanov AG, Bagdasarjan GG. Podvizhnost' i kriterii gotovnosti dental'nyh implantatov k funkcional'nym nagruzkam. Sovremennye problemy nauki i obrazovanija. 2018; (2): 53. 